\title{
VIABILIDADE ECONÔMICA DA IMPLANTAÇÃO DE UM CONJUNTO DE IRRIGAÇÃO - PIVÔ CENTRAL NA PRODUÇÃO DE GRÃOS NO MATO GROSSO DO SUL
}

\author{
Rosalina Maria Alves Rapassi ${ }^{1}$, Antonio Lázaro Sant'Ana ${ }^{2}$, Rodrigo Anselmo Tarsitano ${ }^{3}$, \\ Ercio Roberto Proença ${ }^{2}$
}

1 Professora Doutora em Agronomia, PERPLAN - Pereira Barreto Planejamento Ltda. E-mail: rosa.rapassi@gmail.com.

${ }^{2}$ Professor Doutor do Departamento de Fitotecnia, Tecnologia de Alimentos e Sócio Economia, Universidade Estadual Paulista (UNESP), Faculdade de Engenharia, Câmpus de Ilha Solteira - SP

${ }^{3}$ Professor Doutor, Agronomia, Universidade do Estado do Mato Grosso - UNEMAT; Campus Universitário de Nova Xavantina, MT.

RESUMO: O Brasil ocupa a terceira posição em área irrigável no mundo, atrás apenas da Índia e da China, e a agricultura é a atividade que mais usa água no Brasil. No entanto, da área total cultivada apenas $8,3 \%$ é irrigada, o que indica que há potencial para ampliar a área com irrigação. $\mathrm{O}$ presente trabalho teve como objetivo fazer uma análise do investimento necessário para implantação de um conjunto de irrigação do tipo pivô central para produção de grãos (feijão, milho e soja), na região de Cassilândia, Estado de Mato Grosso do Sul. Foram estimados custos, lucratividades e indicadores de viabilidade econômica do investimento. Verificou-se que o valor a ser investido é alto, pois a implantação do conjunto de irrigação e o preparo inicial do solo são onerosos e as lavouras nesse sistema demandam tecnologia de alto custo. Entretanto, os resultados mostraram viabilidade econômica do investimento, tendo em vista que o retorno ocorreu no quarto ano da produção de grãos. Apesar dos custos maiores do que as lavouras não irrigadas, com conhecimento técnico e acompanhamento rigoroso durante todo o ciclo das culturas, a lucratividade também é maior.

Palavras-chave: Investimentos. Custos. Lucratividades. Feijão. Milho. Soja.

\section{ECONOMICAL VIABILITY OF THE IMPLANTATION OF IRRIGATION - CENTRAL PIVOT, IN THE PRODUCTION OF GRAINS IN THE STATE OF MATO GROSSO DO SUL}

\begin{abstract}
Brazil occupies thirdplace in the world, only behind India and China, concerning irrigable area, and agriculture is the activity that uses more water in Brazil. However, only $8,33 \%$ of the total cultivated area is irrigated, which indicates that there is potential to extend the area under irrigation. This study intended to analyze the investment required to implement a set of center pivot irrigation for grain production (beans, corn, and soybeans), in the area of Cassilândia, State of Mato Grosso do Sul. Costs, profitabilities and indicators of economic viability of the investment were estimated. It was found that the amount to be invested is very high, not only in the implementation of the
\end{abstract}

Cultura Agronômica, Ilha Solteira, v.26, n.4, p.596-610, 2017 
irrigation set and initial preparation of the soil, but also the crops in this system require a more expensive technology, increasing production costs. At the same time, results showed economic viability of the investment, given that the return occurred in the fourth year of

grain production. Despite higher costs than non-irrigated crops, with technical expertise (know-how) and strict monitoring throughout the crop cycle, profitability is also higher.

Key words: Investments. Costs. Profitabilities. Bean. Corn. Soy.

\section{INTRODUÇÃO}

Devido à alta tecnologia empregada na agricultura em busca de maior produtividade e menor risco, muitas áreas utilizam a irrigação, para suprir as necessidades hídricas para o desenvolvimento das plantas na produção de grãos ou de outras atividades. Os benefícios são grandes quando se adota essa técnica no sistema produtivo, pois em um período de seca o risco de quebra de safra é minimizado, com maior garantia de produção.

Dados obtidos na Organização das Nações Unidas para Alimentação e Agricultura (FAO) mostram que a área irrigável no mundo é de 400 milhões de hectares (ha), sendo que a Índia possui a maior área com 139,5 milhões de ha, que corresponde com 35\% do total, seguida pela China com 70 milhões de ha que corresponde a $18 \%$ e o Brasil com uma área de 29,4 milhões de ha que corresponde a $7 \%$ da área total irrigável. Já a área irrigada no mundo é de 310,9 milhões de ha, sendo que a Índia ocupa a primeira posição com 66,3 milhões de ha (21\% do total), seguida pela China com 62,9 milhões de ha (20\% do total), enquanto o Brasil ocupa a $9^{\circ}$ posição com aproximadamente 5,8 milhões de ha, o que corresponde a $2 \%$ do total de área irrigada do mundo (DOMINGUES, 2013).

Apesar do aumento da área total irrigada no Brasil e de sua evolução no cenário mundial (em 1996 o Brasil era apenas o 23 país em termos de área irrigada), estudo do Ministério da Integração Nacional e o Instituto Interamericano de Cooperativismo e Associativismo - MI / IICA (2011) mostra, com base nos dados do Censo Agropecuário do IBGE, que a taxa de crescimento anual da agricultura irrigada tem diminuído ao longo das últimas décadas, passando de 6,5\% no período de 1970-75 para 4,8\% entre 1985-95 e para 3,3\% no período de 1995-2006.

O setor que mais usa água no Brasil é a agricultura em torno de $70 \%$ do total. Como se utiliza menos de $20 \%$ da área potencial de irrigação, Domingues (2013) avalia que é possível dobrar a área irrigada até 2020. Enquanto o MI / IICA (2011) calcula em um cenário pessimista que o aumento deve ser de $55 \%$ e de $119 \%$ em um cenário otimista, até 2030, destacando que devemos lançar mão de fontes de água pouco utilizadas, como a proveniente das águas das chuvas (armazenamento).

No Brasil a região Norte apresenta maior área irrigável (14,6 milhões de hectares), respondendo por quase $50 \%$ da área total irrigável. Em seguida, encontra-se o Centro-Oeste 
com $17 \%$, a região Sul com $15 \%$, o Sudeste $14 \%$ e por último a região Nordeste com $4 \%$ (CHRISTOFIDIS, 2002).

Segundo dados obtidos na Agência Nacional da Água - ANA, a região Sudeste apresenta a maior área irrigada, 2,2 milhões de hectares, representando 38\% da área total irrigada no Brasil, seguida pelo Sul com 1,3 milhões de ha (22,3\%), Nordeste com 1,2 milhões de ha, Centro Oeste cerca de 0,9 milhões ha (14,8\%), Norte com 0,2 milhões de ha $(3,5 \%)$. Verifica-se que a região Norte tem maior disponibilidade de área a ser irrigada, embora com menor taxa de utilização. Já a região Nordeste há menor disponibilidade de área e uma maior taxa de utilização (DOMINGUES, 2013). No entanto, entre 1995 e 2006, foi na região Centro Oeste que ocorreu maior aumento percentual da área irrigada (110\%), seguida da região Sudeste com $71 \%$, Nordeste com $31 \%$, Norte com $30 \%$ e o Sul com apenas 12\% (MI / IICA, 2011).

A Secretaria Nacional de Irrigação - SENIR (BRASIL, 2011), do Ministério da Integração Nacional, criada em 2011, apresenta como seu principal objetivo configurar um sistema de gestão para a agricultura irrigada, articulando os vários órgãos que interagem no setor, apoiando sobremaneira a iniciativa privada e otimizando as áreas públicas como instrumentos de desenvolvimento de regiões menos favorecidas. Além disso, visa promover a irrigação como instrumento de eficiência na produção agrícola e erradicar a pobreza com a geração de emprego e renda. Toda iniciativa de apoiar, articular, informar e promover a melhoria da renda do produtor é bem vinda.

O investimento em um equipamento de irrigação é alto e a sua utilização deve ser muito bem planejada, principalmente em termos de épocas e alternativas de produção. Além disso, o uso da fertirrigação, isto é, aplicação de fertilizantes através da água da irrigação, pode reduzir os custos, conforme dados obtidos por Kaneko et al. (2012).

Silva et al. (2007), também consideram que a irrigação é uma tecnologia que requer investimentos expressivos e está associada à utilização intensiva de insumos, tornando importante a análise econômica dos componentes envolvidos no sistema. Além disso, é uma prática que, além de incrementar a produtividade, pode proporcionar a obtenção de um produto de melhor qualidade e com perspectiva de bons preços no mercado.

Fernandes (2012) ressalta que os sistemas de irrigação são instrumentos importantes para amenizar os impactos das variações climáticas, principalmente na produção de feijão, resultando em aumento na produtividade, mas nada garante que levará a aumento na lucratividade da atividade.

Deve-se ressaltar que em 2014, mesmo o produtor utilizando irrigação e produzindo com eficiência, o preço médio do grão de feijão, que caiu muito no ano, não foi suficiente para cobrir os custos. Daí a necessidade do produtor organizar e controlar bem o seu negócio, técnica e economicamente.

Colleta et al. (2013) procuraram identificar os instrumentos de controle e de análise econômica utilizados pelos produtores de grãos no Mato Grosso do Sul e verificaram que a 
maioria não leva em consideração todos os componentes de custos em seus cálculos, mas acreditam na sua importância na gestão da propriedade.

Desta forma, pretende-se levantar, estimar e avaliar o investimento necessário na implantação de um projeto de irrigação para auxiliar o produtor rural na tomada de decisão. Objetiva-se analisar os custos, a lucratividade e o investimento na implantação de um conjunto de irrigação, tipo pivô central, na produção de grãos de feijão, milho e soja, na região de Cassilândia-MS.

\section{MATERIAL E MÉTODOS}

O Estado de Mato Grosso do Sul é dividido pelo Instituto Brasileiro de Geografia e Estatística - IBGE (2010), em quatro mesorregiões e onze microrregiões geográficas. A pesquisa foi realizada no município de Cassilândia que pertence a Microrregião Geográfica de Cassilândia, que possui área total de $13.223,357 \mathrm{~km}^{2}$ e apresenta população de 60.275 habitantes, dividida em quatro municípios: Cassilândia, Chapadão do Sul, Costa Rica e Paraíso das Águas.

Os dados necessários para a realização da pesquisa foram levantados junto a um agricultor, que é referência na produção de grãos em áreas de sequeiro e irrigada na região oeste de São Paulo e nordeste do Mato Grosso do Sul.

A expansão da cultura da cana-de-açúcar na região oeste de São Paulo levou, além do aumento do valor da terra, a maior dificuldade em conseguir áreas para arrendamento. Produtores tem se deslocado para outras regiões com oferta de áreas maiores a preços menores. O Mato Grosso Sul, mais especificamente a microrregião de Cassilândia, tem apresentado oportunidades para produtores arrendarem terra com implantação de irrigação, por meio de contratos com prazo médio de 12 anos e carência de até 2 anos. O valor do arrendamento situa-se em torno de 12 sacas de feijão/alqueire/ano, já que esta cultura tem sido a atividade principal.

Para levantamento dos dados reais e confiáveis de campo, o produtor está sendo acompanhado em todas as etapas, com registro das informações em planilhas, já que o mesmo também tem demonstrado o interesse em obter análise econômica de suas atividades, em função de sua experiência na produção de grãos.

Foram levantados os custos das etapas para a implantação do conjunto de irrigação pivô central, para o preparo de solo inicial (pré-plantio), para a realização das operações e aplicação de insumos relacionados ao ciclo de cada cultura, desde a dessecação da área até a colheita e comercialização do grão, em uma área de 123,42 hectares.

Após o pré-preparo e a correção da acidez, foi utilizado o sistema de plantio direto no preparo do solo para todas as culturas. Após a dessecação da área com herbicida, foi realizada mecanicamente a semeadura do feijão, cultivar Carioca, no espaçamento de $0,50 \mathrm{~m}$ entre linhas, com 12 sementes por metro de sulco, visando obter uma população de 
aproximadamente 200.000 plantas/ha. Os tratos culturais são os recomendados pela cultura. No caso das culturas de milho e soja foram levantados os insumos e as operações necessários junto ao produtor e também a técnicos (agrônomos) que trabalham com estas culturas na região. Nas operações referentes ao sistema de cultivo, foram estimados os insumos consumidos e o tempo necessário de máquinas e mão-de-obra para a realização de cada operação, definindo os coeficientes técnicos em termos de hora máquina, homem dia e as quantidades utilizadas dos materiais por unidade de área. Os preços dos insumos foram levantados junto à cooperativa que o produtor faz a aquisição desses materiais.

Para análise econômica, como o sistema de cultivo do produtor é produzir três safras em um ano (soja a partir de setembro, milho em fevereiro e o feijão, a partir de junho) e no outro ano duas safras (5 safras em dois anos), para não superestimar os resultados do ano com 3 safras, do valor total obtido com os custos, receitas e lucratividades multiplicou-se por 2,5 .

Para o cálculo do custo de produção das culturas de feijão, milho e soja foi utilizada a estrutura do custo operacional total (COT) e dos indicadores de lucratividade detalhada em Martin et al. (1998). A soma das despesas com as operações mecanizadas, operações manuais, e material consumido, formam o custo operacional efetivo (COE). Acrescentando as depreciações, outras despesas e juros de custeio se obtém o COT.

Foram estimados os seguintes indicadores de lucratividade para as culturas estudadas:

- Receita bruta: constitui-se no produto da quantidade produzida em sacas de $60 \mathrm{~kg}$ pelo preço unitário médio recebido pelo produtor com soja, milho e feijão;

- Lucro Operacional: é a diferença entre a receita bruta e o custo operacional total;

- Índice de lucratividade: refere-se à proporção da receita bruta que se constitui em recursos disponíveis, após a cobertura do custo operacional total;

- Preço de equilíbrio: preço mínimo (por saca de $60 \mathrm{~kg}$ ) necessário para cobrir o custo operacional total; é obtido pela relação entre o COT e a produção média estimada, e

- Produção de equilíbrio: produção mínima (por saca de $60 \mathrm{~kg}$ ) necessária para cobrir o custo operacional total; é obtida pela relação entre o COT e o preço médio estimado.

Os problemas de análise de investimentos, em sua maioria, envolvem decisões de desembolsos de capital a serem realizados no presente que proporcionarão recebimentos de capital em datas futuras. Esta dinâmica dos investimentos faz com que a avaliação econômica realizada tenha como uma de suas mais importantes variáveis o item tempo (BATALHA, 2007).

Das técnicas utilizadas para avaliação de alternativas de investimentos, Nogueira (2007) ressalta três métodos que apresentam rigor conceitual: Valor Presente Líquido 
(VPL), o método da Taxa Interna de Retorno (TIR) e o método do Valor Anual equivalente (VAE) ou Valor Uniforme Líquido.

O Valor Presente Líquido (VPL) define-se como a soma algébrica dos valores descontados do fluxo de caixa de um projeto de investimento, ou seja, é a diferença do valor presente das receitas menos o valor presente dos custos. O projeto que apresenta o VPL maior que zero (positivo) é economicamente viável (NORONHA, 1987). Pode ser calculado como:

$$
\begin{aligned}
& \mathrm{VP}=\sum_{\mathrm{t}=0}^{\mathrm{n}} \frac{\mathrm{Lt}}{(1+\mathrm{i})^{\mathrm{t}}} \\
& \mathrm{i}=\text { taxa de desconto } \\
& \mathrm{VP}=\text { valor presente ou } \mathrm{VPL}=\text { valor líquido } \\
& \mathrm{N}=\text { projeto de horizonte } \mathrm{N}(\mathrm{t}=10 \text { anos }), \\
& \mathrm{L}=\text { fluxo de caixa líquido }
\end{aligned}
$$

O método da Taxa Interna de Retorno (TIR), por definição, é a taxa de juros que torna uma série de recebimentos e desembolsos equivalentes na data presente, isto é, a taxa que torna o valor presente do fluxo líquido igual a zero. O método do Valor Anual Equivalente (VAE) consiste em transformar o fluxo de caixa da alternativa de investimento em análise, em um fluxo de caixa uniformemente distribuído, utilizando-se uma taxa mínima atrativa de retorno (TMAR) (BATALHA, 2007). O VAE representa o lucro descontado que o projeto proporciona a cada ano.

E o payback estima o prazo necessário para que o saldo do investimento seja igual a zero, se ele for menor que o prazo máximo de recuperação do capital investido, o projeto deve ser aceito (BRUNI; FAMÁ, 2012).

Sabbag et al (2012) utilizaram os mesmos indicadores na análise de um investimento realizado na produção de casulo do bicho-da-seda.

\section{RESULTADOS E DISCUSSÃO}

Na Tabela 1, observa-se que o custo com a implantação do conjunto de irrigação e sua instalação foi de $\mathrm{R} \$ 835.100,00$, para uma área de 123,42 ha, ou $\mathrm{R} \$ 6.766,33 / \mathrm{ha}$. A aquisição e montagem do conjunto atingiram $\mathrm{R} \$ 648.000,00$, que corresponde a quase $78 \%$ do total, valor ao qual foram somadas as despesas com a extensão da rede elétrica (800 metros) e aquisição do transformador, o que correspondeu a quase $19 \%$ do total.

A depreciação anual de $\mathrm{R} \$ 41.755,00$ foi estimada considerando vida útil média de 15 anos, o que corresponde a um valor de $\mathrm{R} \$ 338,32 / \mathrm{ha}$.

Para iniciar a produção, além dos investimentos previstos na Tabela 1, também foram necessários investimentos no preparo inicial e na correção (aquisição e aplicação de calcário 
e gesso) do solo, o que resultou em um gasto de $\mathrm{R} \$ 104.879,00$ para 123,42 ha, ou seja, $\mathrm{R} \$ 849,77 /$ ha (Tabela 2). Somente com o calcário foram despendidos mais da metade (quase $55 \%$ ) do total deste valor.

Tabela 1. Investimento na implantação de um conjunto de irrigação tipo pivô central, na região de Cassilândia - MS, em 2013/14.

\begin{tabular}{lr}
\hline Discriminação & Valor (R\$) \\
\hline Protocolo da outorga de água & $1.500,00$ \\
Licenças & $24.000,00$ \\
Limpeza manual da área & $5.000,00$ \\
Construção de 800 m de rede de energia + 1 transformador de 180 kva & $156.600,00$ \\
Aquisição e montagem do pivô central & $648.000,00$ \\
\hline Total & $\mathbf{8 3 5 . 1 0 0 , 0 0}$ \\
\hline Total/ha & $\mathbf{6 . 7 6 6 , 3 3}$ \\
\hline Depreciação/ano & $\mathbf{4 1 . 7 5 5 , 0 0}$ \\
\hline Depreciação /ha & $\mathbf{3 3 8 , 3 2}$ \\
\hline
\end{tabular}

Fonte: Dados da pesquisa de campo.

Tabela 2. Investimento para preparo inicial do solo em 123,42 hectares na região de Cassilândia - MS, 2013/14.

\begin{tabular}{lr}
\hline Discriminação & Valor $(\mathbf{R} \$)$ \\
\hline Aquisição e frete de $400 \mathrm{t}$ de calcário & $56.000,00$ \\
Gesso agrícola & $8.629,00$ \\
Aplicação & $40.250,00$ \\
\hline Total & $\mathbf{1 0 4 . 8 7 9 , 0 0}$ \\
\hline Total/ha & $\mathbf{8 4 9 , 7 7}$ \\
\hline Depreciação/ano & $\mathbf{5 2 . 4 3 9 , 5 0}$ \\
\hline Depreciação/ha & $\mathbf{4 2 4 , 8 9}$ \\
\hline
\end{tabular}

Fonte: Dados da pesquisa de campo.

Ao somar despesas com a aquisição e montagem do conjunto de irrigação e com o preparo e correção inicial do solo, em 123,42 hectares, o total foi de R $\$ 939.979,00$, isto é, $\mathrm{R} \$ 7.616,10 /$ ha. A depreciação anual total foi de $\mathrm{R} \$ 94.194,50$ que foi rateada em 2,5 safras/ano, resultando em um valor de $\mathrm{R} \$ 37.677,80$ por safra agrícola na área total irrigada $(123,42$ ha).

As planilhas de custos foram estimadas considerando a área total do produtor e também para um hectare, que é a unidade utilizada pela maioria dos produtores nas suas planilhas, os custos totais são divididos pela área plantada, gerando uma média por hectare (COLLETA et al., 2013).

A Tabela 3 mostra o custo operacional total (COT) da produção de feijão em 123,42 ha e para um hectare, irrigado, plantio direto, na região de Cassilândia-MS. 
O COT atingiu $\mathrm{R} \$ 446.554,29$ em 123,42 ha ou $\mathrm{R} \$ 3.618,17 /$ ha, do qual as despesas com material consumido representaram quase $44 \%$ deste valor, a seguir estão as despesas com a colheita, em torno de $20 \%$, operações mecanizadas com $11,1 \%$, depreciação do investimento $(8,5 \%)$, gastos com irrigação $(7,8 \%)$, juros de custeio $(4,6 \%)$ e outras despesas $(4,1 \%)$. Destacam-se nos custos totais com a irrigação, as variáveis ligadas à operação do sistema e o custo fixo com a depreciação que somados atingem $\mathrm{R} \$ 51.695,57 \mathrm{em} 123,42$ ha.

Das despesas com material consumido que foi de $\mathrm{R} \$ 195.344,60$, merecem destaque as despesas de $\mathrm{R} \$ 144.539,98$ com fertilizantes (quase $74 \%$ deste item), seguidas com o valor de $\mathrm{R} \$ 29.699,79$ para sementes de feijão (15,5\%) e agrotóxicos com $\mathrm{R} \$ 21.104,82$, representando $11 \%$ do total das despesas com material. A análise das despesas com operações mecanizadas indica que a irrigação se destaca representando 41,4\% do total deste item, seguida pelas despesas com aplicação dos agrotóxicos $(25,6 \%)$. A colheita, que compreende o arranquio, enleiramento e bateção, foi separada das operações e tem grande participação percentual no valor total do COT, cerca de 20\% (Tabela 3).

Tabela 3. Estimativa de custo operacional total, em 123,42 ha, da produção de feijão irrigado, plantio direto, na região de Cassilândia - MS.

\section{Discriminação}

\begin{tabular}{lr}
\hline 1. Operações mecanizadas & $49.593,21$ \\
\hline 2. Irrigação & $34.989,57$ \\
\hline 3. Material Consumido & $29.699,79$ \\
\hline Sementes feijão & $150.710,98$ \\
Fertilizantes & $14.933,82$ \\
Agrotóxicos & $95.344,60$ \\
\hline Sub total (3) & $90.096,60$ \\
\hline 4. Colheita (Arranquio + Enleiramento + Bateção) & $\mathbf{3 7 0 . 0 2 3 , 9 7}$ \\
\hline Custo Operacional Efetivo (COE) & $18.501,20$ \\
\hline Outras despesas (5\% do COE) & $37.677,80$ \\
\hline Depreciação investimento total & $20.351,32$ \\
\hline Juros de Custeio (5,5\%) & $\mathbf{4 4 6 . 5 5 4 , 2 9}$ \\
\hline Custo Operacional Total (COT) & $\mathbf{3 . 6 1 8 , 1 7}$ \\
\hline Custo/ha
\end{tabular}

Na Tabela 4 estão detalhados os coeficientes técnicos e os preços obtidos para estimar o custo operacional efetivo e o custo operacional total para produção de milho sazonal, irrigado, sistema plantio direto na região de Cassilândia-MS.

Verifica-se o custo operacional total (COT) foi de R $\$ 330.753,87$ em 123,42 ha ou R\$ 2.679,00/ha. As despesas com material consumido representaram a metade do COT, a colheita em torno de $16 \%$, a depreciação do investimento $11,4 \%$, as operações mecanizadas quase $8 \%$, irrigação quase $6 \%$, os juros de custeio $4,4 \%$ e outras despesas em torno de $4 \%$. Dentre os materiais consumidos, cujo valor total foi de $\mathrm{R} \$ 165.948,04$, as despesas com Cultura Agronômica, Ilha Solteira, v.26, n.4, p.596-610, 2017 
fertilizantes novamente se destacam com $\mathrm{R} \$ 77.816,31$, representando $47 \%$ do total deste item, enquanto os gastos com sementes que foram de $\mathrm{R} \$ 60.240,04(36,5 \%)$, seguido pelos agrotóxicos que representaram 16,5\% das despesas com material (Tabela 4).

Nas operações mecanizadas, no caso do milho foi o plantio que representou quase a metade (49\%) dos gastos, ao contrário do que ocorreu com a produção de feijão em que se destacam os gastos com as pulverizações.

Tabela 4. Estimativa de custo operacional total, em 123,42 ha, da produção de milho sazonal, irrigado, plantio direto, na região de Cassilândia - MS.

\begin{tabular}{lr} 
Discriminação & \multicolumn{1}{c}{$\begin{array}{c}\text { Valor Total } \\
\text { (R\$) }\end{array}$} \\
\hline 1. Operações mecanizadas & $26.140,48$ \\
2. Irrigação & $19.438,65$ \\
\hline 3. Operações manuais & 259,18 \\
\hline 4. Material Consumido & $60.240,04$ \\
\hline Sementes milho hibrido (sc.) & $77.816,31$ \\
Fertilizantes & 27.891 .69 \\
Agrotóxicos & $165.948,04$ \\
\hline Sub Total (4) & $53.440,86$ \\
\hline 5. Colheita mecanizada e frete & $\mathbf{2 6 5 . 2 2 7 , 2 1}$ \\
\hline Custo Operacional Efetivo (COE) & $37.677,80$ \\
\hline Depreciação investimento total & $13.261,36$ \\
\hline Outras despesas (5\% do COE) & $14.587,50$ \\
\hline Juros de Custeio (5,5\%) & $\mathbf{3 3 0 . 7 5 3 , 8 7}$ \\
\hline Custo Operacional Total (COT) & $\mathbf{2 . 6 7 9 , 9 0}$ \\
\hline COT/ha
\end{tabular}

Na Tabela 5, verifica-se que o COT para produzir 123,42 hectares de grãos de soja, irrigado, sistema plantio direto na região de Cassilândia foi de $\mathrm{R} \$ 260.398,10$ $(\mathrm{R} \$ 2.109,85 / \mathrm{ha})$. Trata-se do menor valor quando comparado com as culturas do feijão $(\mathrm{R} \$ 446.554,29)$ e do milho ( $\mathrm{R} \$ 330.753,87)$.

Novamente despesas com material consumido tiveram maior participação no COT $(43,9 \%)$, seguida pela depreciação que correspondeu a $14,5 \%$, operações mecanizadas $(13,9 \%)$, colheita com $12 \%$, juros de custeio $(4,2 \%)$ e outras despesas representando $3,8 \%$. Destaca-se que pela primeira vez o valor da depreciação com o investimento total, ocupa a segunda posição em importância no custo operacional total.

Do total das despesas com material consumido, $\mathrm{R} \$ 114.354,43$ em 123,42 ha, as despesas com fertilizantes foram maiores, atingindo $\mathrm{R} \$ 69.608,88$ que corresponde a quase $61 \%$, seguida pelas despesas com agrotóxicos (21\%) e com sementes (18\%).

O produtor precisa exercer uma gestão eficiente de todo o seu sistema de produção. Nas planilhas de custos de produção as despesas com fertilizantes se destacaram nas três 
culturas (feijão, milho e soja). Realizar análise do solo para verificar o tipo de adubo e as quantidades corretas de aplicação, é uma medida fundamental para o produtor reduzir os custos, sem perdas na produtividade. No feijão, outro item relevante é a colheita, considerando o arranquio, que é manual, além da bateção do grão; enquanto para a soja e para o milho os valores despendidos com a colheita aparecem na terceira posição em termos de importância. Na segunda posição, na soja, foi o valor da depreciação com o investimento total e no milho foram as despesas com sementes. $\mathrm{O}$ valor da depreciação do investimento com o sistema de irrigação e com o preparo inicial da irrigação também é alto no feijão e ocupou a terceira posição.

Tabela 5. Estimativa de custo operacional total, em 123,42 ha, da produção de soja transgênica, irrigado, plantio direto, na região de Cassilândia - MS.

\begin{tabular}{lr} 
Discriminação & Valor Total (R\$) \\
\hline 1. Operações mecanizadas & $36.273,14$ \\
\hline 2. Irrigação & $19.438,65$ \\
\hline 3. Operações manuais & 388,77 \\
\hline 4. Materiais consumidos & $20.216,20$ \\
\hline Semente de soja (kg) & $69.608,88$ \\
Fertilizantes & $24.519,35$ \\
Agrotóxicos & $114.354,43$ \\
\hline Sub Total (4) & $31.101,84$ \\
\hline 5. Colheita mecanizada e frete & $\mathbf{2 0 1 . 5 5 6 , 8 3}$ \\
\hline Custo Operacional Efetivo (COE) & $37.677,80$ \\
\hline Depreciação do investimento total & $10.077,84$ \\
\hline Outras despesas (5\% do COE) & $11.085,63$ \\
\hline Juros de Custeio (5,5\%) & $\mathbf{2 6 0 . 3 9 8 , 1 0}$ \\
\hline Custo Operacional Total (COT) & $\mathbf{2 . 1 0 9 , 8 5}$ \\
\hline COT/ha
\end{tabular}

Muitas vezes os produtores não consideram os valores das depreciações no seu controle de custos. Colleta et al. (2013) verificaram que $90 \%$ dos produtores entrevistados faziam anotações dos gastos e das receitas obtidas, mas a maioria não considerava os valores das depreciações. Especialmente quando a atividade envolve altos investimentos, como é o caso da irrigação com o conjunto de pivô central, não considerar a depreciação nos custos pode trazer ao produtor uma falsa impressão de lucratividade, devido ao percentual expressivo que representa no COT.

Estimou-se a lucratividade considerando preços médios recebidos pelos produtores, em 2014, pela saca de $60 \mathrm{~kg}$ do grão, que no caso do feijão foi $\mathrm{R} \$ 105,00$, do milho $\mathrm{R} \$ 20,00$ e da soja $\mathrm{R} \$ 50,00$. Os preços médios da saca dos grãos de feijão dos últimos 5 anos é de $\mathrm{R} \$ \$ 123,75$, mas decidiu-se utilizar o preço menor obtido em 2014. No caso do milho e da soja refletem os preços médios dos últimos cinco anos. A produtividade média considerada

Cultura Agronômica, Ilha Solteira, v.26, n.4, p.596-610, 2017 
de 54 sacas de $60 \mathrm{~kg} \mathrm{ha}^{-1}$ do feijão, de 153 sacas de $60 \mathrm{~kg} \mathrm{ha}^{-1}$ para o milho e de 58 sacas de $60 \mathrm{~kg} \mathrm{ha}^{-1}$ para soja, são valores médios obtidos em áreas irrigadas com a tecnologia utilizada pelo produtor.

As estimativas de receita bruta, custo operacional total, lucro operacional e índice de lucratividade, das culturas de feijão, milho e soja e do total para 123,42 hectares, por hectare e anual estão detalhados na Tabela 6.

A cultura do feijão apresenta valores maiores, quando comparado com os valores obtidos para milho e a soja, para a receita bruta, para o custo de produção, para o lucro operacional e o índice de lucratividade (30,51\%) (Tabela 6). Embora a receita bruta do milho seja um pouco maior que a da soja, o custo foi maior para o milho, consequentemente a lucratividade da soja de $27,25 \%$ foi maior do que a do milho que foi de apenas $12,41 \%$. Os índices de lucratividade obtidos no Agrianual (2014), referente a 2013, são maiores que os estimados no trabalho no caso do feijão que atingiu $37 \%$ e da soja (35\%), sendo que somente para o milho foi menor $(10,73 \%)$.

Tabela 6. Estimativas por hectare, da receita bruta total, do custo operacional total, do lucro operacional total e do índice de lucratividade da produção de grãos de feijão, milho e soja, na região de Cassilândia-MS, em 2013/14.

\begin{tabular}{lrrrr}
\hline \multicolumn{1}{c}{ Culturas } & $\begin{array}{c}\text { Receita Bruta } \\
(\mathbf{R} \$)\end{array}$ & $\begin{array}{c}\text { Custo } \\
\text { Operacional } \\
\text { Total (R\$) }\end{array}$ & $\begin{array}{c}\text { Lucro } \\
\text { Operacional (R\$) }\end{array}$ & $\begin{array}{c}\text { Índice de } \\
\text { Lucratividade } \\
(\%)\end{array}$ \\
\hline Feijão & $5.206,61$ & $3.618,17$ & $1.588,44$ & 30,51 \\
\hline Milho & $3.059,47$ & $2.679,90$ & 379,57 & 12,41 \\
\hline Soja & $2.900,00$ & $2.109,85$ & 790,15 & 27,25 \\
\hline Total (3 safras) & $\mathbf{1 1 . 1 6 6 , 0 8}$ & $\mathbf{8 . 4 0 7 , 9 3}$ & $\mathbf{2 . 7 5 8 , 1 6}$ & 24,70 \\
\hline Total (2,5 safras) & $\mathbf{9 . 3 0 5 , 0 7}$ & $\mathbf{7 . 0 0 6 , 6 1}$ & $\mathbf{2 . 2 9 8 , 4 6}$ & $\mathbf{2 4 , 7 0}$ \\
\hline
\end{tabular}

Silva et al. (2007) afirmam que a irrigação pode ajudar muito os agricultores, porém, os riscos da adoção de uma agricultura irrigada devem ser criteriosamente avaliados e minimizados por meio do planejamento cuidadoso das atividades, objetivando sempre que a receita líquida seja maior que os custos. A irrigação é uma tecnologia que requer investimentos altos e está associada à utilização intensiva de insumos, tornando importante a análise econômica dos componentes envolvidos no sistema. O resultado da avaliação econômica mostra a viabilidade ou não da implantação de um sistema de irrigação, portanto este tipo de estudo pode ser instrumento importante para formar a decisão do produtor. 
Tabela 7. Fluxo de caixa, VPL, VAE, TIR e Pay Back para implantação da irrigação na produção das culturas de feijão, milho e soja para área total (123,42 ha), na região de Cassilândia (MS), 2013/14.

\begin{tabular}{|c|c|c|c|c|c|c|c|}
\hline $\begin{array}{l}\text { ITENS } \\
\text { ENTRADAS (R\$) }\end{array}$ & 1 & 2 & 3 & 4 & 8 & 9 & 10 \\
\hline Receita bruta & & $1.148 .431,67$ & $1.148 .431,67$ & $1.148 .431,67$ & $1.148 .431,67$ & $1.148 .431,67$ & $1.148 .431,67$ \\
\hline \multicolumn{8}{|l|}{ SAÍDAS (R\$) } \\
\hline Implantação & $-939.979,00$ & & & & & & \\
\hline Custo oper. total - depreciação & & $770.560,72$ & $770.560,72$ & $770.560,72$ & $770.560,72$ & $770.560,72$ & $770.560,72$ \\
\hline Fluxo de caixa líquido (FCL) & $-939.979,00$ & $377.870,95$ & $377.870,95$ & $377.870,95$ & $377.870,95$ & $377.870,95$ & $377.870,95$ \\
\hline FCL acumulado & $-939.979,00$ & $-562.108,05$ & $-184.237,10$ & $193.633,84$ & $2.082 .988,59$ & $2.460 .859,53$ & $2.838 .730,48$ \\
\hline FCL descontado & $-939.979,00$ & $356.482,03$ & $336.303,80$ & $317.267,73$ & $237.080,91$ & $223.661,23$ & $211.001,16$ \\
\hline FCL descontado acumulado & $-939.979,00$ & $-583.496,97$ & $-247.193,17$ & $70.074,56$ & $1.406 .521,68$ & $1.630 .182,91$ & $1.841 .184,07$ \\
\hline VPL & 1.841.184,07 & & & & & & \\
\hline VAE & 250.157,92 & & & & & & \\
\hline TIR & $38,67 \%$ & & & & & & \\
\hline Payback & $3^{\circ}$ ano & & & & & & \\
\hline Payback econômico & $3^{\circ}$ ano & & & & & & \\
\hline
\end{tabular}


Na Tabela 7 estão detalhados os resultados da viabilidade econômica da implantação da irrigação na produção de grãos (dados para área total de 123,42 hectares), na região de Cassilândia (MS), 2013. Verificou-se que o valor presente líquido (VPL) foi de $\mathrm{R} \$ 1.841 .184,07$, considerando uma taxa de desconto de 6,0\% a.a. Quanto maior o VPL, mais desejável é o projeto, pois maior é seu potencial de ganho. A Taxa Interna de Retorno (TIR) foi de $37,98 \%$, maior que a taxa de desconto, e quanto maior a distância entre o valor da taxa de desconto e da TIR, menor é o risco, e, neste caso, o capital investido é recuperado no $3^{\circ}$ ano. O valor anual equivalente foi $\mathrm{R} \$ 250.157,92$, isto é, o lucro atual (descontado) que o projeto proporciona a cada ano.

Se a receita bruta total cair até $20 \%$, o projeto ainda seria viável, o VPL seria igual a $\mathrm{R} \$ 150.672,67$, e a TIR de 9,27\% seria maior que a taxa de desconto, mas o payback econômico, ou seja, o investimento inicial no projeto só seria recuperado no $9^{\circ}$ ano.

Fernandes (2012) também verificou resultados positivos no investimento em um sistema de irrigação. Analisando o retorno e o risco do investimento na produção de feijão irrigado em Minas Gerais, obteve o VPL de R\$3.147,00 e a TIR de 17\%, que foi maior que a taxa mínima de atratividade do capital. Os resultados mostraram que a probabilidade é de $90 \%$ da TIR estar no intervalo de $15,6 \%$ a $18,13 \%$, tornando o projeto atrativo e de baixo risco.

\section{CONCLUSÃO}

Nas condições analisadas na pesquisa conclui-se:

- O investimento é alto, não só na implantação do conjunto de irrigação e no investimento inicial com o preparo e correção do solo, mas também com a produção de feijão, milho e soja irrigados que elevam os custos de produção;

- As despesas com material consumido se destacam nas planilhas de custos de produção de grãos, sobretudo as despesas com fertilizantes e com a colheita;

- A cultura do feijão apresentou maiores custos, receita bruta e lucratividade, seguida pela soja e milho;

- Obteve-se viabilidade econômica na implantação de um conjunto de irrigação tipo pivô central, para produção de grãos, sendo que o retorno ocorreu no $3^{\circ}$ ano;

É fundamental o manejo eficiente da irrigação, definindo quanto e quando irrigar, realizar análise do solo e definir com base no resultado obtido, o tipo e as quantidades adequadas de fertilizantes a serem utilizadas, e a colheita deve ser realizada na época certa, procurando reduzir perdas que ocorrem no campo. Enfim, o manejo correto das culturas, o uso da fertirrigação e controle fitossanitário rigoroso também contribuem para reduzir o risco de quebra de safra, com maior garantia de produção e consequentemente melhor resultado econômico. 


\section{REFERÊNCIAS BIBLIOGRÁFICAS}

AGRIANUAL: Anuário da agricultura brasileira. São Paulo: Informa economics South America/FNP, 2014. 463p.

BATAlHA, M. O. Gestão Agroindustrial. 3. ed., v. 1, n. 2. São Paulo: Ed. Atlas, 2007. $770 \mathrm{p}$.

BRASIL. MINISTÉRIO DA INTEGRAÇÃO NACIONAL. IRRIGAÇÃO / SECRETARIA NACIONAL DE IRRIGAÇÃO - SENIR. Apresentação. 2011. Disponível em: http://www.integração.gov.br/web/guest/apresentação-senir. Acesso em: 22 agosto 2014.

BRUNI, A. L., FAMÁ, R. As Decisões de Investimentos. 3. ed. São Paulo: Atlas, 2012. $197 \mathrm{p}$.

CHRISTOFIDIS, D. Irrigação, a fronteira hídrica na produção de alimentos. Irrigação e Tecnologia Moderna. n. 54. Brasília: ABID, 2002. p. 46-55.

COLlETA, B. K. D.; CEZAR, I. M.; SOUZA, C. C.; COSTA, F. P. Instrumentos de gestão financeira utilizados pelos produtores de grãos de São Gabriel do Oeste, Mato Grosso do Sul. Revista Agrarian, Dourados, v. 6, n. 21, p.346-357, 2013.

DOMINGUES, A. F. O potencial da agricultura irrigada - Agroinvest. nov. 2013. Disponível em http://www.canaldoprodutor.com.br/sites/default/files/14h10_AntonioFelixDomingues_Inve stimentoIrrigacao.pdf . Acesso em: 03 abr. 2014.

FERNANDES, L. M. Retorno financeiro e risco de preço da cultura do feijão irrigado via pivô central na região noroeste de Minas Gerais. Informações Econômicas, São Paulo, v. 42, n. 1, p.41-53, 2012.

INSTITUTO BRASILEIRO DE GEOGRAFIA E ESTATÍSTICA - IBGE. Indicadores Demográficos do Estado de Mato Grosso do Sul - 2010. Disponível em: http://www.ibge.gov.br/estadosat/perfil.php?sigla=ms . Acesso em: 15 jul. 2013.

KANEKO, F. H.; HERNANDEZ, F. B. T.; SHIMADA, M. M.; FERREIRA, J. P. Estudo de caso - Análise econômica da fertirrigação e adubação tratorizada em pivôs centrais considerando a cultura do milho. Revista Agrarian, Dourados, v. 5, n. 161, p.161-165, 2012 .

MARTIN, N. B.; SERRA, R.; OLIVEIRA, M. D. M.; ANGELO, J. A.; OKAWA, H.. Sistema integrado de custos agropecuários - CUSTAGRI. Informações Econômicas, São Paulo, v. 28, n. 1, p.07-28, 1998.

MINISTÉRIO DA INTEGRAÇÃO NACIONAL/INSTITUTO INTERAMERICANO DE COOPERATIVISMO E ASSOCIATIVISMO - MI / IICA Organização, descrição, análise e interpretação de dados sobre a agricultura irrigada no Brasil. Brasília, 2011. 68 p. Disponível

em:

Cultura Agronômica, Ilha Solteira, v.26, n.4, p.596-610, 2017 
http://www.iica.int/Esp/regiones/sur/brasil/ArquivosMultimidia/Material_exibido_IVReunia o_intercambio/Painel04_estatistica_irrigacao_albuquerque.pdf . Acesso em 13 set. 2014.

NOGUEIRA, M. P. Gestão de Custos e Avaliação de Resultados. 2. ed. Bebedouro: Scot Consultoria, 2007. 244p.

NORONHA, J. F. Projetos Agropecuários: administração financeira, orçamentação e viabilidade Econômica. 2. ed. São Paulo: Atlas, 1987. 269 p.

SABBAG, O. J.; NICODEMO, D.; OLIVEIRA, J. E. M. Custos e viabilidade econômica da produção de casulos do bicho-da-seda. Pesquisa Agropecuária Tropical, Goiânia, v. 43, n. 2, p.187-194, 2013.

SILVA, M. L. O.; FARIA, M. A.; REIS, R. P.; SANTANA, M. J.; MATTIOLI, W. Viabilidade técnica e econômica do cultivo de safrinha do girassol irrigado na região de Lavras, MG. Ciência e Agrotecnologia, Lavras, v. 31, n. 1, p.200-205, 2007. 